Int. J. Electrochem. Sci., 15 (2020) $7242-7259$

International Journal of ELECTROCHEMICAL

SCIENCE

$\underline{\text { WWW.electrochemsci.org }}$

Mini review

\title{
A Brief Review of Post-Lithium-Ion Batteries
}

Tatiana L. Kulova ${ }^{1,2}$, Vladimir N. Fateev ${ }^{1}$, Ekaterina A. Seregina ${ }^{1}$, Alexander S. Grigoriev ${ }^{l}$

${ }^{1}$ National Research Center «Kurchatov Institute», 1, Akademika Kurchatova sq., Moscow, Russia, 123182

${ }^{2}$ Frumkin Institute of Physical Chemistry and Electrochemistry of the RAS, 31-4 Leninskii ave., Moscow, Russia, 119071

"E-mail: tkulova@mail.ru

doi: $10.20964 / 2020.08 .22$

Received: 2 April 2020 / Accepted: 15 May 2020 / Published: 10 July 2020

Energy storage is an extremely important problem today. Among the most efficient batteries, lithiumion occupy a special place. Lithium is the most active known reducing agent. It has a huge energy storage resource. $1 \mathrm{~kg}$ of lithium is capable of storing 3860 ampere-hours. However, lithium-ion batteries have almost reached their limits and are characterized by a high cost, which raises the question of the further development of such technologies based on the so-called post-lithium-ion batteries. This paper provides an overview of post-lithium-ion batteries such as lithium-oxygen batteries, sodium-ion batteries, lithiumsulfur batteries and their comparison with known lithium-ion batteries. The commercialization of postlithium-ion batteries is also discussed.

Keywords: Lithium-ion batteries; Lithium-oxygen batteries; Sodium-ion batteries; Lithium-sulfur batteries; Post-lithium-ion batteries

\section{FULL TEXT}

(C) 2020 The Authors. Published by ESG (www.electrochemsci.org). This article is an open access article distributed under the terms and conditions of the Creative Commons Attribution license (http://creativecommons.org/licenses/by/4.0/). 